\title{
ECONOMIA SOLIDÁRIA À LUZ DO AMBIENTE ISONÔMICO DE GUERREIRO RAMOS: vivências do 'Grupo de Mulheres Decididas a Vencer'
}

\section{1- Geyson Eliakim Ferreira de Araujo*}

Mestre em Administração pela Universidade Federal do Rio Grande do Norte (PPGA/UFRGN), Brasil. ge_eliakim@hotmail.com

http://lattes.cnpq.br/3566312162155903

\section{2- Juarez Azevedo de Paiva}

Mestre em Administração pela Universidade Federal do Rio Grande do Norte (PPGA/UFRGN), Brasil. Professor Colaborador na Universidade Federal do Rio Grande do Norte (PPGA/UFRGN), Brasil.

juarez.paiva@ig.com.br

http://lattes.cnpq.br/4082836424132032

\section{3- Washington José de Souza}

Doutor em Educação pela Universidade Federal do Ceará (UFC), Brasil

Professor Associado no Programa de Pós-Graduação em Administração (PPGA/UFRN), Brasil.

wsouza@ufrnet.br

http://lattes.cnpq.br/2387611219688981

\section{4- Denise Cristina Momo}

Mestranda do Programa de Pós-Graduação em Administração pela Universidade Federal do Rio Grande do Norte (PPGA/UFRN), Brasil.

Professora Substituta do Departamento de Ciência Contábeis (DCC/UFRN) da Universidade Federal do Rio Grande no Norte (UFRN), Brasil.

denisecmomo@yahoo.com.br

http://lattes.cnpq.br/5157055493166643 


\section{ECONOMIA SOLIDÁRIA À LUZ DO AMBIENTE ISONÔMICO DE GUERREIRO RAMOS: VIVÊNCIAS DO 'GRUPO DE MULHERES DECIDIDAS A VENCER'}

\section{RESUMO}

Através do constructo de isonomia do Paradigma Pareconômico de Ramos (1989), o presente texto busca evidenciar, características de ambiente isonômico, em vivências econômico-solidárias, tomando como espaço de investigação empírica o 'Grupo de Mulheres Decididas a Vencer', localizado em um assentamento rural no município de Mossoró/RN. Para o estudo foi adotada a hipótese da possibilidade de haver convergências entre princípios de Economia Solidária e o construto isonomia, de acordo com Guerreiro Ramos (1989), ambos vistos como manifestações organizacionais em que o senso coletivo prevalece diante do individual e oportuniza aos participantes a autorrealização. Para tanto, foi empregada estratégia de pesquisa exploratório-descritiva, de natureza qualitativa, que tomou como informantes o conjunto das sócias do empreendimento, dentre as mais atuantes. A partir das cinco categorias que caracterizam a isonomia - prescrição mínima de normas, atividade autogratificante, atividade realizada como vocação, sistema amplo de tomada de decisão e relações interpessoais primárias - e de traços característicos de empreendimento econômico solidário, foi desenvolvida uma análise de conteúdo das falas na perspectiva categorial. Foi possível chegar à conclusão de que o Grupo compartilha vivências e características de isonomia.

\section{Palavras-chave}

Paradigma Paraeconômico; Isonomia; Economia Solidária.

\section{SOLIDARITY ECONOMY IN THE LIGHT OF THE ISONOMIC ENVIRONMENT OF GUERREIRO RAMOS: EXPERIENCES OF THE 'MULHERES DECIDIDAS A VENCER GROUP'}

\section{ABSTRACT}

Through the construct of equality on Ramos' (1989) para-economic paradigm, this article outlines isonomic environmental characteristics in solidarity-economy experiences, taking the 'Mulheres Decididas a Vencer Group', located in a rural settlement in the county Mossoró/RN, as an object of empirical research. For this study we adopted the hypothesis of convergence between principles of solidarity economy and the construct of equality, according to Ramos (1989), both viewed as organizational manifestations in which the collective sense prevails before the individual and nurture members' self-actualization. Therefore, an exploratory and descriptive search strategy, of qualitative nature, was used and took as informants all the members of the enterprise among the most active. From the five categories that characterize equality minimum prescription standards, self-gratifying activity, activity performed as a vocation, wide system of decision making and primary interpersonal relationships - and the features of a solidarity economic enterprise, we developed an analysis of the speech's content in a categorical perspective. It was possible to conclude that the group shares experiences and characteristics of equality.

\section{Keywords}

Para-economic Paradigm; Equality; Solidarity Economy. 


\section{Introdução}

A Economia Solidária não é apenas uma alternativa à amenização do desemprego e à superação de situações vulneráveis de trabalho, mas, também, uma perspectiva de organização sócio-política de indivíduos e segmentos populacionais. A Economia Solidária, mapeada até 2007, tem predominância na área rural sob a forma de associação de pequenos produtores, consumidores e comerciantes. De acordo com o SIES - Sistema de Informação da Economia Solidária (http://www.mte.gov.br), no estado do Rio Grande do Norte, por exemplo, aproximadamente $70 \%$ dos empreendimentos econômicos solidários são provenientes do meio rural e $74 \%$ são associações. Apenas $9 \%$ são cooperativas (SIES, 2007).

É nesse cenário que está imerso o Grupo de Mulheres Decididas a Vencer, associação rural, localizada no Assentamento de Mulugunzinho no município de Mossoró, desde 1997, criada a partir do apoio do Centro Feminista 8 de Março (CF8) visando á formação sócio-política das mulheres para a participação nas decisões inerentes à comunidade. A partir daí, o grupo se organizou e, por meio da participação em encontros e seminários em temas como agroecologia, relações de gênero e Economia Solidária, passou a atuar de modo diferenciado no Assentamento ${ }^{1}$.

O grupo tem história de conquistas e desenvolvimento econômico, político, social e cultural em sua trajetória. Formado exclusivamente por mulheres e criado como forma de emancipação econômica destas perante os maridos, o grupo é exemplo de que a inserção no espaço da Economia Solidária possibilita o crescimento em várias esferas da vida.

É com base no modo como se estrutura e funciona esse grupo de trabalho e produção, que se buscou a isonomia como forma organizacional e alternativa para além do modo como operam as típicas organizações de mercado. De acordo com Ramos (1989), a isonomia, um dos enclaves ${ }^{1}$ do Paradigma Paraeconômico, permite a emancipação humana em relação aos ditames do mercado, pois, nela as atividades desenvolvidas se tornam por si autogratificantes. A isonomia, uma vez guiada pela racionalidade substantiva, pode possibilitar a autorrealização ${ }^{2}$ dos membros, através da atividade produtiva, da consciência crítica (saber analisar e construir entendimento questionador a respeito de algo), da liberdade política, da prescrição mínima de regras e da busca pelo desenvolvimento social amplo.

A isonomia é um dos aspectos da multidimensionalidade dos sistemas sociais propostos no Paradigma Paraeconômico. Este é tomado como condutor de uma inflexão na teoria administrativa diante do que se vem estudando desde a Administração Científica. Ramos (1989) reconstrói - a partir do Paradigma, por ele tomado como um arcabouço que delimita sistemas sociais - a teoria das organizações em virtude da ênfase que esta concede ao mercado. Por essa razão, elabora críticas aos fundamentos da teoria das organizações convencionalmente aceita.

Ramos (1989) afirma que o Paradigma Paraeconômico é parte de uma obra inacabada, apresentada, portanto, como esforço preliminar. Autores como Ventris e Candler (2005) e Serva (1997), defendem que uma nova ciência pode não vingar pela insuficiência de robustez empírica. Serva (1997), em trabalho acerca da racionalidade nas organizações, mostra que existe um "impasse", por ele definido como uma "substancial lacuna" no campo dos estudos organizacionais. O autor constatou a precariedade de trabalhos que se referem à racionalidade em virtude da ausência de constatações empíricas. Perante tal fato, o presente trabalho pretende contribuir na aplicabilidade da proposta de Ramos mediante o estudo da prática administrativa de um empreendimento econômico solidário, trazendo, como resultado final, possíveis evidências empíricas do conceito de isonomia no fato administrativo. Todavia, as evidências empíricas poderá contribuir para a aplicabilidade do paradigma paraeconômico, primeiramente, em virtude do processo de interação entre o pesquisador e os sujeitos da pesquisa e depois, pela possibilidade de manifestações de outras variáves não suscitadas no modelo teórico de Ramos, (1989).

Diante dos traços acima citados, Economia Solidária e isonomia podem ser vistas como construtos passíveis de sincronia, permitindo aproximações entre ambos e novas possibilidades de estudos no campo da Gestão Social, a exemplo do trabalho de Serva (1997) que tratou da aplicabilidade conceitual do par de racionalidades - instrumental e substantiva - na prática administrativa.

A partir desse entendimento, questiona-se aqui a possível validade conceitual do ambiente isonômico, quando aplicado a organizações econômico-solidárias, a partir do seguinte problema: o Grupo Mulheres Decididas a Vencer, no campo empírico, evidencia vivências econômico-solidárias com características de ambiente isonômico? 
Em busca de tais evidências, a pesquisa foi direcionada para: a) identificar o nível de formalização de normas e procedimentos internos; b) traçar o sentido atribuído ao trabalho com base nos princípios da vocação ${ }^{3}$ das trabalhadoras para a atividade produtiva desenvolvida; c) identificar a utilidade atribuída aos resultados alcançados; d) caracterizar o processo de tomada de decisão na organização em estudo, tomando como referência a participação dos membros; e) circunstanciar relações interpessoais no empreendimento visando à identificação de mutualidades e flexibilidade nos relacionamentos ${ }^{4}$.

\section{Referencial Teórico}

\subsection{O Conceito de Isonomia no Paradigma Paraeconômico}

Diante da ideia de que em cada tipo de sociedade está arraigada uma noção de racionalidade, Ramos discorre acerca das características que uma abordagem substantiva da organização poderia manifestar. A primeira delas é o entendimento de que "os limites da organização deveriam coincidir com seus objetivos" (Ramos, 1989, p. 134). Ele se refere à extrapolação dos limites da organização econômica para a vida humana em geral. Essa suplantação da organização econômica pode ser ilustrada pelos traços da "síndrome comportamentalista" e na figura do "formalismo", que, "na realidade, tornou-se um traço normal da vida cotidiana, nas sociedades centradas no mercado, onde a observância das regras substitui a preocupação pelos valores éticos substantivos" (Ramos, 1989, p. 59).

A segunda característica está na concepção de que não é possível ao homem se autodesenvolver inserido numa organização pautada pelo comportamento administrativo, pois, a conduta individual, no contexto das organizações econômicas, está, fatalmente, subordinada a compulsões operacionais, formais e impostas. Assim sendo, o comportamento administrativo é intrinsecamente vexatório e incompatível com o pleno desenvolvimento das potencialidades humanas. (Ramos, 1989, p. 135). Em outras palavras, não é possível ao homem a autorrealização tendo sua razão, sua criatividade e sua liberdade para se expressar circunscritas a condutas administrativas com nítido intuito econômico. É importante frisar que Ramos não é contrário à manifestação da organização econômica típica. Ele não admite, isto sim, que esta se propague como propensão única do comportamento humano. A organização econômica típica alicerça seus objetivos no desenvolvimento econômico mercantil e não na ideia da felicidade e do bem-estar de indivíduos e coletividades.

A terceira característica é a ideia de que "a organização econômica é apenas um caso particular de diversos tipos de sistemas microssociais [ ...]" (Ramos, 1989, p. 135). Observa-se que o pensamento de Ramos é sempre voltado ao entendimento de que existem limites entre os vários sistemas sociais e que cada um tem objetivos e alcances particulares, o que não retratado pela teoria das organizações.

A quarta característica aponta que a abordagem substantiva “[ ...] preocupa-se, sistematicamente, com os meios de eliminação de compulsões desnecessárias agindo sobre as atividades humanas nas organizações econômicas e nos sistemas sociais em geral" (Ramos, 1989, p. 135). É um espaço de compensação para o homem que o permite desvincular-se dos entraves do comportamento administrativo e buscar satisfação pessoal.

A racionalidade substantiva é tomada como manifestação alternativa à instrumental sem substituí-la. Tem como principio primário a ética, que fundamentaria, segundo Ramos (1989), a ação que levaria à superação do comportamento instrumental, possibilitando ao indivíduo atingir a autorrealização e o autodesenvolvimento. Polanyi (2000) já havia discorrido acerca da concepção substantiva, quando afirmou que o mercado e a racionalidade instrumental não eram os únicos elementos de todos os tipos de economia. Ou seja, outras formas de economia (não-mercantil e não-monetária) deveriam ser vistas sob prismas diferentes, com sendo compostas por outros elementos (Serva, 1997).

Partindo da crítica à racionalidade instrumental, predominante na sociedade de mercado, e fundamentando-se em princípios da racionalidade substantiva, Ramos (1989) propõe outros enclaves sociais voltados às necessidades humanas: o Paradigma Paraeconômico. Volta-se a sanar a "miopia" da teoria organizacional - de natureza mercadocêntrica - e a leitura unidimensional do "modelo de análise e planejamento de sistemas sociais que ora predomina nos campos da administração, da ciência política, da economia e da ciência social em geral [ ...]" (Ramos, 1989, p. 140).

O Paradigma muda a leitura convencional do pensar e do agir nas organizações, reformulando conceitos no intuito de antever possibilidades à emancipação do homem na sociedade. Baseado na ideia 
de que existem vários espaços para as relações humanas, além do mercado, Ramos (1989) apresenta o Paradigma como opção ao que hoje se denomina de sociedade de mercado. Mostra um lado multicêntrico, em que caberia a um dado sistema de governo formular e regular políticas públicas, responsáveis por manter coeso o sistema multidimensional, pautado na racionalidade substantiva. É importante destacar que Ramos (1989, p. 140) compreende os sistemas sociais de tal paradigma como "[ ...] elaborações heurísticas, no sentido weberiano". Deixa claro que a imbricação entre os sistemas torna quase impossível que exista um sistema isolado sem receber e provocar influências nos demais.

Em contraposição ao modelo humano unidimensional pressuposto pela ciência social moderna, Ramos (1989) traça três pressupostos que caracterizam o Paradigma Paraeconômico. O primeiro deles é a existência de diversos enclaves “[...] onde há descontinuidades de diversos tipos, múltiplos critérios substantivos de vida pessoal e uma variedade de padrões de relações interpessoais". O segundo é que o homem, só “incidentalmente [...] é um maximizador da utilidade e seu esforço básico é no sentido da ordenação de sua existência de acordo com as suas próprias necessidades de atualização pessoal". Isto quer dizer que a natureza do individuo, em essência, não é a busca do cálculo, do objetivo econômico (esse é apenas adjacente ao principal), mas, sim, da satisfação e do desenvolvimento pessoal (Ramos, 1989, p. 141). O terceiro pressuposto é que "[ ...] o indivíduo não é forçado a conformar-se inteiramente ao sistema de valores de mercado", em outras palavras, existem outros espaços que o homem pode ocupar.

Em suma, o Paradigma Paraeconômico propõe uma delimitação organizacional pautada na existência de diferentes sistemas sociais, imbricados e com limites, que possibilitam ao indivíduo escolhas em se ocupar naquele que melhor se adéque ao desenvolvimento próprio. Como dito acima, é constituído de diversos enclaves ou "categorias delimitadoras" (Ramos, 1989, p. 146), dentre eles, a isonomia, a economia, a fenonomia, o motim, a anomia e o isolado. (Ramos, 1989). Cada categoria possui traços próprios, que a diferencia das demais, e limites que determinam seu espaço. No entanto, eles não são dicotomizados, ou seja, a imbricação e a convivência entre esses espaços na sociedade é fato, tornando o espaço social multidimensional.

Cada enclave encontra-se regulado por um ente maior, qual seja, o sistema de governo. Este, com poder redistributivo, na concepção proposta por (Polanyi, 2000), delimitaria o espaço de cada enclave através da formulação e implementação de “[ ...] políticas públicas que promovessem o ponto ótimo de transação entre os enclaves sociais" (Paula, 2007, p. 183). Conforme a Figura 1, Ramos (1989) estabelece dois critérios: no eixo vertical, a prescrição e ausência de normas e, no eixo horizontal, a orientação individual e a comunitária.

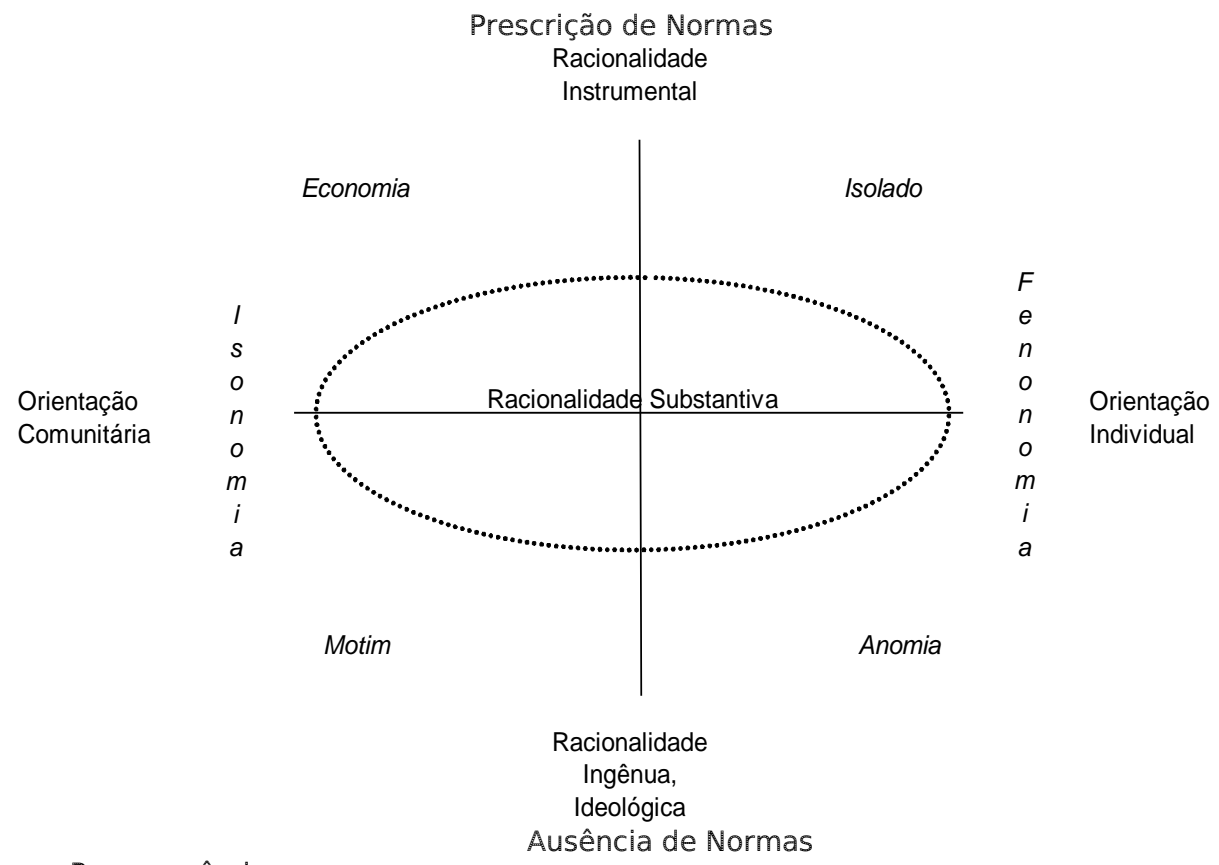

Figura 1 - Paradigma Paraeconômico

Ausência de Normas

Fonte: Adaptado de Ramos (1989, p. 141). 
No quadrante circunscrito pela prescrição de normas, com orientação comunitária, encontra-se o enclave economia. No quadrante circunscrito pela ausência de normas, com orientação comunitária, está o motim. No lado esquerdo, no quadrante da prescrição de normas com orientação individual, reside o isolado, ao passo que, no quadrante inferior - orientação individual sob ausência de normas - reside o enclave da anomia. Todos eles são elementos extremos no Paradigma e, por essa razão, Ramos (1989) os trata como categorias heurísticas, informando que, no plano empírico, tais enclaves não se apresentam em estado puro, integral. Assim sendo, a ideia de que a economia é um enclave, que se situa na prescrição de normas com orientação comunitária, não implica no entendimento de que toda e qualquer ação econômica tenha exclusivamente esse viés, ou, ainda, que seja completamente guiada pela prescrição ou pela orientação comunitária.

É exatamente entre os extremos do Paradigma Paraeconômico que estariam os enclaves da isonomia (com orientação comunitária) e da fenonomia (com orientação individual), ambos com predominância da racionalidade substantiva, mediados, por um lado, pela prescrição e, por outro, pela ausência de normas. Na isonomia, portanto, há um ponto intermediário, uma espécie de equilíbrio entre a prescrição e a ausência de normas, com orientação comunitária. Nas palavras de Ramos (1989, p. 150), ela "[...] pode ser definida como um contexto em que todos os membros são iguais". Disso se presume a carga de coletividade que uma organização deste tipo pressupõe e a complexidade de se organizar tal igualdade. Para ilustrá-la, o autor menciona a polis, conforme concebida por Aristóteles, como sendo "uma associação de iguais, 'construída por amor a uma boa vida'" A política, I, ii, 125b, § 8 (Ramos, 1989 , p. 150). Pela complexidade que demanda a constituição de uma isonomia e pela distância de tempo do exemplo dado, pode-se imaginar improvável tal organização coexistir com organizações presentes na sociedade contemporânea. No entanto, ele deixa claro que não se trata de uma nostalgia sem fundamento, mas, sim, de uma proposta direcionadora de possíveis ambientes sociais desse tipo.

Ramos (1989), na ideia de construir linhas que delimitassem o enclave isonômico, propõe alguns direcionamentos para que este possa existir.

O primeiro deles é o que delimita a isonomia entre a prescrição e a ausência de normas. A isonomia deve ter prescrições mínimas, e, quando existirem, devem ser estabelecidas por consenso. Esse fato se dá pela necessidade dos membros atualizarem-se sem que obstáculos utilitários os impeçam. Na opinião do autor, é quase impossível que numa organização com prescrições em demasia, o homem possa se emancipar. "Tal processo apenas reforça a tendência de despersonalização do indivíduo" (França Filho, 2010, p. 182). É pertinente questionar por a existência de prescrições, mesmo que mínimas, em tal enclave, forçando Ramos (1989, p. 146) a responder que "a total eliminação de prescrições e de normas é incompatível com uma significativa atualização humana, no contexto do mundo social". A total eliminação de normas seria contrária às ideias de coletividade que pressupõem a isonomia, haja vista que a atualização - que pode ser definida como a consciência crítica do homem para o que o rodeia e suas implicações, bem como a escolha da melhor opção para que o desenvolvimento social possa existir na totalidade, expurgado do interesse utilitarista - é inerente a ela. A não prescrição de normas caracteriza outros enclaves, a anomia, com orientação coletiva, e o isolado, com orientação individual. Em ambos, a vida pessoal e social tende a desaparecer (Ramos, 1989).

A segunda peculiaridade da isonomia a conforma como um ambiente que permite desenvolver atividades autogratificantes, em que os membros participam de grupos que possam proporcionar-Ihes um tipo generoso de relacionamento social (Ramos, 1989, p. 150). Numa isonomia, o que se procura não é a obrigação de um trabalho enfadonho e rotineiro para satisfazer necessidades básicas, alimentares e de segurança. Ao contrário, busca-se satisfazer necessidade de afeto e relacionamento, de ajuda mútua, que engrandece o homem na medida em que existe reciprocidade, na concepção de (Polanyi, 2000) entre os membros, diferentemente de uma obrigação velada, no sentido de subjugação de um pelo outro, como é encontrada no enclave mercado (Ramos, 1989). Nas palavras de Ramos (1989, p. 150), “[ ...] as pessoas não ganham a vida numa isonomia; antes participam de um tipo generoso de relacionamento social, no qual dão e recebem.". Numa isonomia supera-se o mito de que só é possível existir felicidade no progresso e no crescimento econômico (Ramos, 1989).

Outra particularidade da isonomia está relacionada à distinção entre ocupação e trabalho. Ramos (1989) diferencia esses dois elementos interligando cada um a um tipo de racionalidade, instrumental e substantiva. O trabalho estaria relacionado à racionalidade instrumental, pois é “[ ...] a prática de um esforço subordinada às necessidades objetivas inerentes ao processo de produção em si." (Ramos, 1989, p. 130). Na sociedade vigente, o trabalho é considerado como a porta de entrada para a socialização. No 
entanto, tal socialização estaria arraigada a objetivos instrumentais, nos quais os resultados finais são interesses individuais. Ao contrário do que ocorre na ocupação.

A terceira característica seria atividade realizada como vocação. Na visão de Ramos (1989, p. 130), “a ocupação é a prática de esforços livremente produzidos pelo indivíduo em busca de sua atualização pessoal". Ou seja, mesmo com esforços, busca-se realização nos objetivos que determinada atividade requer e não na renda que ela pode gerar. Embasando-se na conceituação de Ramos de trabalho e ocupação, pode-se fazer uma distinção entre os termos, por meio de um exemplo: digamos que se oferece formação escolar a uma comunidade através de capacitações de cunho social e político. Isto pode significar uma forma de auferir renda, caso financiada, estando o instrutor interessado no valor do pagamento pelo trabalho, mas, de outra forma, pode significar uma forma de autorrealização pela gratificação com a atividade, que promove consciência crítica e social de indivíduos. Portanto, essa particularidade da isonomia a coloca numa posição de organização que permite às pessoas realizarem aquilo que realmente gostam, tendo a necessidade de renda como secundária.

Do quarto traço, que distingue a isonomia dos demais enclaves, pode-se dizer que é o mais importante para constituí-la como tal. "O sistema de tomada de decisão e de fixação de diretrizes políticas é totalmente abrangente." (Ramos, 1989, p. 150). A importância dessa característica é evidenciada por Ramos em Administração e contexto brasileiro, quando delimita o fato administrativo ${ }^{5}$. Este, baseado na ideia de fato social, proposto por Durkheim, possui três categorias: os elementos estruturantes, estruturais e a-estruturais. O elemento estruturante é aquele que define como os outros se conformarão; é o mais importante, e se ilustra na figura da tomada de decisão. Isto porque, segundo Ramos (1989), a palavra administração já pressupõe dinamicidade e tal dinâmica só é possível através da decisão, permitindo, assim, que as coisas aconteçam. A tomada de decisão é variável central do elemento estruturante no fato administrativo, seja qual for o tipo de organização. É o elemento que permite avaliar uma organização como sendo abrangente politicamente, quando atribuída por deliberação de todos, sem diferenciação entre gerência e subordinados. Tal processo abrangente é característico da isonomia, pois, é centrado em relações hierárquicas horizontais.

Por isso, para a última peculiaridade da isonomia, Ramos (1989) propôs a prevalência das relações interpessoais primárias em detrimento das relações formais. A busca pela emancipação humana se dá pela relação entre iguais e, assim, não existe diferença de tratamento e decisão entre membros ou atividades.

Em suma, a isonomia poderia ser descrita em poucas palavras como:

sítio para o exercício da convivência, e seu principal requisito temporal é uma experiência de tempo em que aquilo que o indivíduo ganha em seus relacionamentos com as outras pessoas não é medido quantitativamente, mas, representa uma gratificação profunda por se ver liberado de pressões que the impedem a atualização pessoal (Ramos, 1989, p. 169).

No geral, ao observar a ideia da multidimensionalidade de sistemas, proposta por Ramos (1989), percebe-se a possibilidade do homem se atualizar quando tem noção do espaço e do limite de cada uma das categorias delimitadoras, escolhendo, assim, em qual prefere atuar, não se restringindo apenas ao enclave economia.

A partir desses pressupostos é possível traçar analogias com princípios da Economia Solidária, cujas características centrais são a seguir expostas.

\subsection{Contextualizando a Economia Solidária}

A sociedade atual está imbuída por uma racionalidade instrumental sem precedentes. Nem na época da luta de classes pensada por Marx o capitalismo conseguiu uma legitimação, quanto a que se encontra presente nos dias atuais. Hoje se vive, literalmente, uma sociedade de mercado, regida por princípios e fundamentos de um enclave, que se tornou único na vida cotidiana de grande parte da população mundial, o enclave econômico, sustentado pelo modo de produção capitalista (Gaiger, 2003 ).

A lógica mercantil e os valores que a acompanham ocupam espaços cada vez maiores na vida das pessoas, extrapolando a vida econômica e invadindo dimensões mais substantivas da vida humana associada (França Filho \& Laville, 2004), como menciona Polanyi (1992) "ao invés da economia estar embutida nas relações sociais, são as relações sociais que estão embutidas no sistema econômico". Onde é 
Economia solidária à luz do ambiente isonômico de Guerreiro Ramos: vivências do 'Grupo de Mulheres Decididas a Vencer'

esquecido que o termo economia não está limitado apenas à troca mercantil, mas sim um termo mais amplo que representa um conjunto de atividades que contribuem para produção e distribuição de riquezas.

A extrapolação dos limites desse enclave chegou a organizações como a família. Na idade média as famílias tinham um código de ética próprio, que as caracterizavam perante a sociedade; hoje o seu código de ética é o da organização econômica; no seu âmbito as relações e os laços são construídos margeados por elementos como competitividade e um individualismo exacerbado, que vão destruindo aos poucos elementos antes enaltecidos como o amor, a solidariedade, fraternidade e a paciência. Toda essa dominação, então, começa a ser criticada por alguns movimentos sociais que se vêem oprimidos diante da imposição de normas antiéticas sendo arraigadas no seio da conduta humana, normalmente, como se fosse da sua natureza (Singer, 2002).

Não se pode deixar de notar o direcionamento que esses movimentos sociais possuem com as idéias da racionalidade substantiva. Acrescentando a esses princípios, o da solidariedade, da cooperação e da responsabilidade social pode-se dizer que as organizações provenientes desse movimento podem estar inseridas entre as fronteiras de alguns dos enclaves propostos por Ramos (1989).

Entretanto, alguns sinais indicam que a Economia Solidária ainda está muita imbuída dos princípios de uma sociedade de mercado. Entre esses sinais encontram-se as relações de poder assimétricas existentes entre os diferentes atores da rede como mostrado por Costa (2007), quando sumaria algumas características de empreendimentos relatados em diversas obras literárias, entre elas a necessidade de poder competir no mercado capitalista, por isso mesmo precisando de estratégias que muitas vezes direcionam-se excessivamente para a racionalidade instrumental.

Alguns autores (Costa, 2007; França Filho \& Laville, 2004; Gaiger, 2004; 2007; Singer \& Souza, 2000) apontam que no âmbito da Economia Solidária seja quase impossível expurgar definitivamente aspectos da economia capitalista, visto que a mesma encontra-se inserida numa economia de mercado e necessita sobreviver, demandando relações assimétricas com instituições econômicas. É uma utopia pensar que a Economia Solidária irá substituir todo um sistema capitalista.

O termo Economia Solidária é recente (segunda metade do século $X X)^{6}$, mas, os seus princípios, como a cooperação, a autonomia e a gestão democrática, já eram propagados em períodos remotos (Laville \& Gaiger, 2009). A partir de meados do século XIX, esses princípios se tornaram bandeiras do movimento cooperativista, conduzidas por operários da época da Revolução Industrial, inspirados no pensamento e experiências de Robert Owen em empreendimentos sociais em New Lanark, comunidade localizada em Lanark (Escócia) ${ }^{7}$. Princípios similares estão presentes em pensamentos de outros socialistas, a exemplo de Fourier, que faz alusões à vida coletiva a partir dos falanstérios, lugar onde as decisões seriam tomadas pelos indivíduos em assembleias e não haveria motivo para a competição exacerbada (Konder, 1998).

Pensamentos dessa natureza decorreram da luta contra as mazelas trazidas pela Revolução Industrial. Na Europa, as primeiras cooperativas se formaram devido ao distúrbio social que a industrialização ocasionou com práticas de rápido crescimento de cidades e indústrias, racionalizando processos produtivos, ao tempo em que gerava instabilidades no campo e na cidade. Tal fenômeno engajou indivíduos com motivos semelhantes a atividades coletivas, pela via do reformismo e do cooperativismo, diferentemente do que pregava a ruptura pela via do socialismo.

Um revigorado movimento com esse viés ganhou força com a chegada de militantes da esquerda ao poder, em países da América Latina e França, quando se observou a possibilidade de que princípios da economia de mercado e da economia solidária poderiam conviver num mesmo espaço (Laville \& Gaiger, 2009). No Brasil, o movimento ganhou forma a partir de 1980 e foi impulsionado na metade dos anos 1990 , resultante da crise do emprego, neste caso, devido, além de outros fatores, à abertura do mercado interno à competitividade estrangeira (Singer \& Souza, 2000).

Das ações concretas que envolveram o conceito de Economia Solidária, primeiramente, destaca-se o trabalho das Cáritas, entidade da Conferência Nacional de Bispos do Brasil (CNBB), no meio rural, os empreendimentos que surgiram da falência de empresas, pela tomada da administração por parte dos trabalhadores, que passaram a praticar a autogestão, além das Incubadoras Tecnológicas de Cooperativas Populares (ITCPs), instituições formadas por entidades universitárias voltadas ao suporte técnico, social e político a grupos sociais em situação vulnerável de trabalho e renda (Singer, 2002). 
Foi em meio a esse movimento, em nível nacional, que o Governo Federal criou a Secretaria Nacional de Economia Solidária vinculada ao Ministério do Trabalho e Emprego (SENAES/MTE), criada em 2003 como uma importante ação para o fortalecimento do movimento cooperativista numa perspectiva popular. Veio com a função de abarcar essa demanda "[ ...] visando à geração de trabalho e renda, à inclusão social e à promoção do desenvolvimento justo e solidário" (http://www.mte.gov.br). Passou o Governo Federal do atendimento a ações pontuais, para atendimento a demandas em nível nacional, concretizadas pela socialização de princípios e valores como dignidade, ajuda mútua, autogestão e solidariedade, pilares adotados para o crescimento político, sócio-ambiental e econômico.

Desde que os empreendimentos desse movimento começaram a ter êxito, estudiosos se propuseram a entender sua viabilidade, não só em cooperativas, mas, também, em associações e grupos informais. Algumas concepções de Economia Solidária vão florescendo conforme os estudos vão se multiplicando e características, fundamentos e princípios vão se proliferando. Não há proposta de rompimento com a economia tradicional com viés capitalista. Por isso, torna-se pertinente fazer considerações acerca do conceito de Economia Solidária a partir da concepção de Economia Plural.

Segundo França Filho e Laville (2004), vivemos numa sociedade cuja lógica mercantil e os valores que a acompanham ocupam espaços cada vez maiores na vida das pessoas, extrapolando a vida econômica e invadindo dimensões mais substantivas da vida humana associada, como menciona Polanyi (2000) "ao invés da economia estar embutida nas relações sociais, são as relações sociais que estão embutidas no sistema econômico". Onde é esquecido que o termo economia não está limitado apenas à troca mercantil, mas sim um termo mais amplo que representa um conjunto de atividades que contribuem para produção e distribuição de riquezas.

Estudo feito por Souza e Lins (2007), demonstrou que a Casa Viver, não merece a denominação quanto ao Paradigma Paraeconômico, segundo as premissas que caracterizam isonomia, adotada por Ramos (1989). Pois, quando analisado o gerenciamento da instituição, foi constatado junto aos funcionários que os elementos da racionalidade instrumental e substantiva se manifestam e se interagem numa convivência permanente e contínua em todos os processos, em todos os níveis hierárquicos, bem como nas relações entre os demais níveis.

França Filho (2003) vê a Economia Solidária como um tipo organizacional que convive e dialoga com - sistema de mercado, que, por sua vez, possui pluralidade de economias e tensões entre lógicas diferentes. O autor converge com Ramos (1989) na ideia de que a economia de mercado é apenas uma forma social possível entre outras e que os empreendimentos econômicos solidários estariam "[ ...] numa busca de equilíbrio, necessariamente frágil e muito difícil, entre lógicas distintas [ ...]" ilustrada pela tensão entre três economias (mercantil, não-mercantil e não-monetária), “[ ...] ou entre duas lógicas (instrumental e substantiva)" (França Filho, 2003, p. 7). Essas ideias são concebidas a partir de Polanyi que expõe várias formas de produzir e distribuir riquezas ao longo da história, reconhecendo a existência de diferentes princípios econômicos: o mercado auto-regulado, a redistribuição, a reciprocidade e a domesticidade ${ }^{8}$ (Polanyi, 2000).

A economia plural é entendida como "[ ...] toda forma de produzir e distribuir riquezas [...]" admitindo a coexistência num mesmo espaço organizacional de uma economia mercantil, uma economia não-mercantil (estatal-redistributiva) e não-monetária (agrupa os princípios da reciprocidade e domesticidade) (França Filho, 2003, 2008). Isso é possível, pois, no espaço da Economia Solidária, existe a convivência de elementos de diferentes dimensões, como a “[ ...] venda de um produto ou prestação de um serviço (recurso mercantil); subsídios públicos oriundos do reconhecimento da natureza de utilidade social da ação organizacional (recurso não-mercantil) e trabalho voluntário (recurso não-monetário)" (França Filho, 2002, p. 13).

Essa noção de economia plural traz consigo singularidades às práticas de economia solidária, entre elas "[ ...] a possibilidade de enxergar a economia solidária como uma articulação inédita dessas três formas de economia, inventando outro modo de instituir o ato econômico [...]", não substituindo a economia vigente, mas como uma forma alternativa de produzir e distribuir riqueza, sem a noção distorcida de uma "nova economia [...] ocupando um setor à parte num papel funcionalmente bem definido em relação ao conjunto" (França Filho, 2008, p. 8). A segunda singularidade direciona para o entendimento de que nas práticas de economia solidária existem "tensões nas dinâmicas organizativas" dessas diferentes lógicas (substantiva e instrumental), buscando o equilíbrio entre elas para alcançar uma sustentabilidade (França Filho, 2008, p. 8). 
Assim, verifica-se que os empreendimentos econômicos solidários surgem sob o questionamento da priorização da lógica de mercado, mas, inbuídos dentro de uma lógica instrumental e substantiva e diante das disfunções geradas por esta lógica que acarreta em mudanças na dinâmica sócio-econômica e o surgimento de grandes crises econômicas (Lechat, 2002).

Lisboa (2005) traz a visão da racionalidade instrumental e substantiva em outra perspectiva, da socieconomia solidária, ou seja, a Economia Solidária não é movida nem pela lucratividade máxima do capital, nem pela elevação do interesse individual, unindo na sua essência o emocional na preocupação com o indivíduo, com o econômico, na busca de resultados. Essa nova dinâmica permite expressar a economia, não mais como um fim supremo, mas sim, como uma ferramenta que tem por objetivo o sustento da vida e a melhoria da condição humana.

Nessa nova dinâmica nas relações de trabalho verificamos o aumento de novas formas de relações de trabalho e economia no Brasil, a Economia Solidária “surge como modo de produção e distribuição alternativo ao capitalismo, criado e recriado periodicamente pelos que se encontram (ou temem ficar) marginalizados do mercado de trabalho" (Singer, 2000, p.13). A economia solidária materializa-se através de empresas falimentares autogeridas, cooperativas e associações; os quais denominamos de Empreendimentos Econômicos Solidários (EES).

É, pois, este, o cenário dos empreendimentos econômicos solidários: praticam estratégias de gestão que, simultaneamente, os submete à convivência com elementos da racionalidade instrumental, como comercializar em mercado competitivo e auferir renda, e, de outra forma, ao diálogo com valores de solidariedade, pela via do trabalho associativo e da ajuda mútua - componentes de racionalidade substantiva. São dilemas dessa natureza que, a seguir, se encontram em discussão na busca por traços de isonomia no Grupo pesquisado.

\section{Procedimentos Metodológicos}

Esta pesquisa é do tipo exploratório-descritiva por almejar o alcance de evidências de isonomia, com base no Paradigma Paraeconômico (Ramos, 1989), a partir de um empreendimento econômico solidário. É descritiva, pois, aponta a realidade de um empreendimento considerado econômico solidário, buscando identificar traços de isonomia. Devido ao tipo de análise e forma como foram coletados os dados, a pesquisa, quanto à natureza, é qualitativa.

Trata-se igualmente de estudo de caso por se tratar de investigação realizada a partir de um único empreendimento. O estudo foi desenvolvido no Grupo de Mulheres Decididas a Vencer, o qual possui atualmente quinze membros, que se divide em: grupo de caprinoovinocultura, grupo da horta e grupo da apicultura, foram escolhidas apenas seis mulheres, de maior participação nas atividades produtivas. A pesquisa foi realizada, mediante o emprego de três instrumentos de coleta de dados: a entrevista individual semi-estruturada e a entrevista em grupo, como instrumentos principais, e a observação, como instrumento auxiliar. O estudo de campo foi construído in loco, no período de oito dias, entre 9 e 16 de janeiro de 2010.

O estudo foi realizado no Grupo de Mulheres Decididas a Vencer, o qual possui atualmente quinze membros, porém, pelo nível de atividade e por estarem inseridas no Grupo Produtivo (divide-se em: grupo de caprinoovinocultura, grupo da horta e grupo da apicultura) escolheram-se apenas seis mulheres como sujeitos da pesquisa.

A pesquisa foi iniciada com as entrevistas individuais, semi-estruturadas, a partir das quais foram coletadas informações acerca do estado em que se encontrava o empreendimento do ponto de vista do conceito de isonomia. A entrevista semi-estruturada, segundo Triviños (2007, p. 146), “[ ...] ao mesmo tempo em que valoriza a presença do investigador, oferece todas as perspectivas possíveis para que o informante alcance a liberdade e a espontaneidade necessárias, enriquecendo a investigação.".

Após a fase da entrevista individual, foi desenvolvida uma entrevista com todo o grupo. Esse momento foi importante por permitir a construção da história do empreendimento. A entrevista em grupo se fez necessária ao estudo por permitir que a realidade social fosse construída em conjunto (Flick, 2004). Patton (1990 como citado em Flick, 2004) mostra a importância desse instrumento na superação de obstáculos e inconsistências, evitando opiniões falsas e radicais e permitindo a visualização de opinião compartilhada. 
O tipo de observação utilizada foi a sistematizada, já que foram levadas a campo categorias de análise pré-estabelecidas relacionadas à isonomia (prescrição mínima de normas, atividade autogratificante, atividade realizada como vocação, sistema amplo de tomada de decisão e relações interpessoais primarias). A observação se construiu em diversas situações, tais como em momentos informais e de trabalho e reuniões. As anotações foram subsidiadas por fotos e filmagens, assim como pela observação direta dos pesquisadores. A análise dos dados, das três fases de coleta, seguiu as cinco dimensões da isonomia como categorias centrais do estudo.

Para a entrevista individual, a análise de conteúdo se mostrou a técnica mais adequada, pela riqueza operacional de coletar informações úteis a partir do discurso e mensagens externadas. Foi utilizada, como uma das técnicas de análise de conteúdo, a análise categorial. Bardin (1977, p. 153) define a análise categorial como sendo aquela que "funciona por operações de desmembramento do texto em unidades, em categorias segundo reagrupamentos analógicos.". As categorias utilizadas foram as cinco características (mencionados acima) trabalhadas por Ramos (1989) na construção do conceito de isonomia.

Os dados decorrentes da observação sistematizada foram analisados a partir da descrição da rotina de trabalho do empreendimento. Buscou-se confrontar os dados coletados das entrevistas individuais e em grupo com a realidade observada em campo.

\section{A Isonomia na Prática Associativa}

O Grupo de Mulheres Decididas a Vencer foi constituído em 1997, no Assentamento de Mulugunzinho, localizado no Município de Mossoró no Rio Grande do Norte (RN). Na época do primeiro Mapeamento Nacional da Economia Solidária, realizado em 2003, o Grupo foi definido pelas integrantes como sendo do tipo informal, atuante na área rural e urbana. Tem como atividades a plantação de hortifrutigranjeiros, a criação de caprinos e ovinos e a produção de mel (apicultura). Formado por quinze mulheres, é subdividido em grupos menores, chamados de Grupos Produtivos: caprinovinocultura, apicultura e horta. A principal motivação para a formação do grupo foi a emancipação das mulheres em relação aos maridos, principalmente financeira. Tem, na base da gestão, o ato associativo. Do resultado da produção, parte é destinada ao comércio e outra ao autoconsumo.

Para a análise dos dados da pesquisa no Grupo, tornou-se pertinente o resgate das categorias que constroem o conceito de isonomia. Conforme exposto anteriormente, Ramos (1989) propõe a existência de características básicas (prescrição mínima de normas, atividade autogratificante, atividade realizadas como vocação, sistema amplo de tomada de decisão e relações interpessoais primárias) que, uma vez manifestas em conjunto, configuram a isonomia organizacional.

A primeira delas é a prescrição mínima de normas, ou seja, a isonomia caracteriza-se por possuir regras mínimas à boa convivência entre os membros, sob reduzido apego a traços burocráticos. Tomando como base esse conceito, o Grupo de Mulheres Decididas a Vencer foi analisado e constatou-se considerável proximidade entre a realidade por elas vivenciada e o conceito de prescrição mínima de normas. Há poucas regras vigentes, a exemplo de algumas atas de reuniões, horário de trabalho e um quadro de distribuição individual das atividades. Nas palavras da Associada 1 é possível observar a restrita existência de regras:

O que a gente tem é em ata, vamos dizer, os equitares que a gente tem hoje de terra foi doada em "assembreia" pelo sócios. A gente tem isso em ata: colocar tantos equitares pro Grupo de Mulheres. (A1)

É pertinente registrar que o espaço cultivado pelas Mulheres foi cedido pela Associação do Assentamento, da área comum de manejo, em assembleia.

A observação direta evidenciou que a confiança mútua prevalece nas relações de trabalho e produção, mediante restrito emprego de registros formais. As mulheres prezam por iniciar as atividades no horário estipulado, sem, contudo, existir sanções quando há descumprimento ou atraso. São sempre buscadas alternativas com as que estão presentes, ou, de outro modo, é providenciada substituição quando possível e necessária. A existência de um cartaz no espaço da horta, definindo as atividades do dia, sem especificar quem irá realizá-las, confirma a flexibilidade na distribuição das responsabilidades internamente. 
Ficou evidente que a atividade-fim do Grupo não é prejudicada em virtude do reduzido grau de burocracia. Ao contrário, tal fato é fundamental à qualidade dos relacionamentos e garante o que o autor chama de relacionamentos primários, ou seja, relações de todos em um único nível, horizontalmente, sem intermediários que possam caracterizar a existência de níveis hierárquicos.

As categorias atividade autogratificante e atividade realizada como vocação foram analisadas conjuntamente, pois, há certa complementaridade entre ambas. Essas categorias podem ser caracterizadas, segundo Ramos (1989), como as que proporcionam um tipo generoso de relacionamento social, ou seja, é o praticar atividades buscando a satisfação pessoal e social, por meio, principalmente, da reciprocidade e da confiança e do respeito mútuos.

Para representar essas categorias, foram utilizados questionamentos relacionados ao sentimento das associadas quando estão trabalhando no grupo, tais como: o que mais e o que menos as satisfaz durante a realização das atividades; os benefícios oferecidos pelo Grupo às integrantes; as garantias porventura existentes.

Os sentimentos expressos foram significativamente positivos, evidenciados em termos como felicidade, companheirismo, amizade, auto-estima e liberdade. Quando questionadas a respeito do que mais causava satisfação durante a realização das atividades, todas as associadas destacaram pontos que dizem respeito a traços que se relacionam à concepção teórica de ocupação (Ramos, 1989), pois, o trabalho não aparece dissociado de outras dimensões da vida. A fala da Associada 2 é elucidativa:

A amizade é o que dá satisfação, né? A felicidade de cada uma, que a gente tem; que a gente tem como conversar, botar os assuntos em dia, participar das mágoas... de tudo. (A2).

Outra ponto ilustrativo foi trazido pela Associada 4, ao inserir uma palavra pouco usual quando se fala acerca de trabalho:

É uma terapia, sabe? Apesar de tá trabalhando, ao mesmo instante é uma coisa que a gente se sente feliz, eu sou feliz lá [ ...]. (A4).

Apesar da presença de sentimentos considerados nobres, relacionados às atividades praticadas, observou-se que o aspecto instrumental aparece na fala de quatro mulheres do grupo.

Para a Associada 3, o destaque é a formação técnica para as atividades de apicultura e de hortaliça:

O curso que eu sei, que foi mais importante foi o de apicultura porque até hoje, foi um curso que a gente fez e a gente bota em prática, porque a gente trabalha com abelha. O de hortaliça também foi muito importante, que a gente também trabalha, mas é uma coisa... foi uma coisa mais fácil. O de abelha pra mim é um coisa mais difícil por isso que eu acho que ele foi o mais importante (A3).

Para a Associada 4, o diferencial está na utilidade do benefício:

[ ...] foi o da caixa de cinquenta mil litros d’água, porque, através disso, aí a gente viu a horta crescer, né? A gente viu a horta crescer, a gente viu... eh... levar produtos pra os consumidores e, ainda mais, a feira livre, né? (A4).

A Associada 5 destaca o benefício da afinidade com a capacitação oferecida:

O curso que a gente já aprendeu com [Associada 3] lá na horta, curso de picles, pa fazer picles. É muito gostoso... de quiabo, melhor ainda do que cenoura e beterraba. Eu gosto muito. Gostei muito dele. (A5).

A Associada 6 evidencia a possibilidade de obtenção de renda e a liberdade financeira que a atividade acarreta:

O Grupo Feminista deu aquele apoio a gente de... de a gente... que a gente produzia os nossos produto e não... num tinha aquela lógica de tirar nosso renda daí. E... e através das reunião com o Grupo Feminista, aí nós foi alertando a gente pra gente... trabai... eh... daquela produção a gente tirasse o nosso... a nossa renda. Que nós fizesse um meio de vida, né? (A6). 
O que se observa na fala das associadas, são elementos de racionalidade instrumental, tratados por Serva (1997), como ideias de ganho, cálculo, relação meios-fins. Não obstante a preocupação de algumas mulheres com renda e outros elementos da racionalidade instrumental, na observação foi possível evidenciar, tanto nas conversas informais, quanto durante reuniões e na realização das atividades, que essa preocupação é secundária. Todas elas evidenciam o caráter libertador que o Grupo trouxe, especialmente em virtude da possibilidade de informações acerca de direitos e deveres, na direção das relações de gênero, da reivindicação junto ao Estado e do espaço na sociedade.

O Grupo é igualmente libertador porque as tirou do anonimato, tanto na vida doméstica quanto junto à comunidade, onde passaram a ser chamadas de "mulheres que incomodam, que zoam". Assim, mesmo com registros de traços instrumentais, o benefício maior, talvez, seja essa percepção renovada de mundo. A Economia Solidária, aqui, passa por duas dimensões de racionalidade: a substantiva e a instrumental. Isto reafirma o posicionamento de Laville e Gaiger (2009), França Filho $(2002,2008)$ e França Filho e Laville (2004) no tocante à Economia Solidária como manifestação de economia plural, mediante a presença de elementos mercantis, não-mercantis e não-monetários.

A quarta categoria se mostra como elemento estruturante na construção da isonomia: o sistema amplo de tomada de decisão. Quando define o fato administrativo, Ramos (1983) elege a decisão como o componente político central que assume o papel de elemento estruturante. Por sua vez, o sistema de decisões em uma isonomia deve permitir que todos os membros de uma organização possam ter participação ativa no processo de tomada de decisão de forma igualitária (Ramos, 1989), evidenciando amadurecimento político e democracia interna.

Essa categoria está presente no Grupo de Mulheres Decididas a Vencer de diversas formas. Um delas reside no modo como a informação, seja ela de reduzida ou de elevada importância, é repassada entre as integrantes do Grupo. Nesse sentido, ficou evidenciado o modo como se processa a transparência na divulgação das informações entre todas as integrantes do grupo, pois, se pressupõe que uma organização, quando regida por princípios igualitários, divulga amplamente as informações no âmbito interno.

A forma como a decisão é tomada, por meio de assembleias, é destacada pelas associadas:

Eu acho que a assembleia é importante porque, quando tem um grupo de mulheres, assim, que a gente decide uma coisa que quem ganha é a maioria, é muito importante a gente tomar uma decisão onde tá todo mundo junto, onde é a opinião de todo mundo [ ...] (A3).

A opinião da maioria das mulheres do Grupo converge para o entendimento de que, independentemente do conteúdo da decisão, o procedimento adotado não muda. Dito de outro modo, qualquer que seja a decisão, de menor ou de maior relevância, o sistema de tomada de decisão segue o mesmo procedimento básico - a ampla participação de todas:

São todas decisões assim: reunir; em reunião, cada qual dá sua opinião e as que der certo sair, é as que vai. O que a gente ver que tem mais futuro, para aplicar alguma coisa, é o que é decidido. (A6).

Frente aos traços aqui analisados, no que se refere ao componente político da gestão - a decisão - o modo como esta acontece se aproxima das propriedades de sistema amplo de tomada de decisão, referenciado por Ramos (1989) na construção do conceito de isonomia.

A quinta e última categoria da isonomia é a prevalência de relações primárias, em contraposição a relações formais hierarquizadas. Para Ramos (1989), a noção de isonomia perpassa pela efetivação de relacionamentos desvencilhados de rituais burocráticos, comuns às organizações formais. $O$ cerne da isonomia é, conforme dito anteriormente, a igualdade entre os membros, e, assim, relações primárias tendem a facilitar o alcance de tal valor por permitir livres relacionamentos entre todos, sem qualquer tipo de intermediação. Para ilustrar a presença dessa categoria no Grupo estudado, foram buscados aspectos relacionados ao modo como se manifestam a liderança e os relacionamentos entre as associadas e, ainda, influências de tais relacionamentos no desempenho.

O intuito, no primeiro aspecto, foi retratar o tipo de liderança predominante no Grupo e como esta se constituiu e se manifesta. Quatro das seis associadas consideram que a liderança é realizada em conjunto, e, assim, todas são líderes. As Associadas 2 e 3 deixam nítido o papel de todas na condução do Grupo:

Todas. Todas as mulheres lideram. (A2)

Ninguém lidera o Grupo [ risos]. Somos nós; somos nós juntas [ ...]. (A3) 
Economia solidária à luz do ambiente isonômico de Guerreiro Ramos: vivências do 'Grupo de Mulheres Decididas a Vencer'

Todavia, duas das associadas apontam uma das integrantes como a líder de fato, conforme ilustra a seguinte fala:

Eh... o grupo... a gente... tem uma pessoa que lidera, que é $A 1$, né? Ela sempre tá a parte de mais, de mais informação, porque ela tá sempre mais lá fora. E, outra coisa, ela tem mais essa habilidade de liderar mesmo o grupo, né? (A4).

A maneira como a liderança foi constituída, de acordo com os dois depoimentos, se torna relevante ao entendimento da existência de sentimentos de igualdade entre as associadas. A liderança se dá de forma democrática. Nas duas falas o entendimento é que a líder está sempre "lá fora", viajando, trazendo "novidades". Há mulheres que preferem viver no Assentamento - na tranquilidade da vida rural, com filhos, esposo e vizinhos - e se negam a viagens, à participação em eventos, ainda que sob estímulo da líder e da Entidade de Apoio e Fomento (EAF) que acompanha o Grupo, o Centro Feminista 08 de Maio. Outras, especialmente no caso da associada nominada como líder, não se negam a tais empreitadas e, com sentimento de contribuição para o bem coletivo, viajam, participam de eventos e representam o Grupo em feiras.

De fato, há certo predomínio da liderança de A1, em modo similar à fala acima. A associada A1 é referência no Grupo, não apenas internamente (ainda que de modo não unânime), mas, também, dentro do movimento da Economia Solidária no Rio Grande do Norte e no Brasil. A razão é justamente esta apontada pela associada A4: ela participa ativamente dos eventos relacionados à Economia Solidária, mostrando-se sempre disponível a viagens e entusiasmada em participar e acompanhar a agenda do movimento em âmbitos regional, estadual e nacional. A líder conseguiu se desenvolver com mais facilidade nas capacidades da oratória e da persuasão e as utiliza quando necessário.

Segundo a Associada 1, no grupo existem pessoas com habilidades distintas e que se sobressaem às demais a partir de tais habilidades. Por isso, têm liberdade para demonstrar atitudes de liderança quando da realização de determinadas tarefas, porém, impera o sentimento coletivo:

[...] o que poderia existir é uma que tem... é isso que eu digo... de... a que faz a contabilidade, a quem tem o olhar de todo, de dizer: ah, tem um canteiro que nasceu, tem um canteiro... tem pessoas que têm essa facilidade de observar, de dizer, mas, a decisão, olhe, vamo replantar de novo, é do coletivo (A1).

Portanto, do mesmo modo que há mulheres que têm facilidades para observar e conduzir as condições de produção de um canteiro há aquelas, que se mostram interessadas e dispostas a viagens. As escolhas são acatadas. É o viés democrático, então, que autoriza a Associada 5 a não identificação da presença de uma líder, mas, sim, de uma gestão coletiva. Por essa razão, afirma que todas são iguais no Grupo:

Foi a gente mesmo que decidiu ser todas igual, mandar todas igual lá na horta. Não uma só mandar, né, em todas. Foi a gente mesmo." (A5).

É pertinente destacar que, mesmo entre as duas mulheres que identificam uma das Associadas no exercício da liderança do Grupo, há o registro de que a definição ocorreu de modo consensual:

Foi nas reunião, na reunião, né? Porque sempre quem tinha mais disposição pra tá fora era ela e quem tava mais por dentro dos assuntos, essas coisas, ai ela ficou. (A6).

Tal liderança, apesar de observada durante a pesquisa de campo e ser fato inquestionável entre os conhecedores da trajetória do Grupo, não caracteriza qualquer nível de hierarquização ou de autoridade superior da associada em relação às demais, pois na falta da líder, as demais mulheres desempenham suas atividades norlamente, tomando decisões de forma coletiva.

Além da manifestação de liderança em modos restritos (ao que parece está muito mais voltada ao papel político da representação do Grupo em eventos externos), a relação primária é nítida e facilmente observável no cotidiano de trabalho. Outro aspecto que caracteriza a existência de relações primárias, conforme registrado anteriormente, reside no processo de tomada de decisão que é amplo, transparente, participativo e democrático. 
Predomina a informalidade nos relacionamentos internos entre as associadas. O ambiente de trabalho é descontraído e as atividades do lar convivem com as do trabalho e vice-versa, ganhando, estas últimas, características de terapia, conforme falas das associadas A1 e A4.

Nos depoimentos seguintes fica evidente a preocupação com a liberdade de expressão:

Todo grupo tem pensamentos opostos, uma pessoa quer uma coisa a outra quer outra. Eh... a opinião é diferente; os dedos das mão, nenhum é perfeito, não são igual [ ...]. A gente tem direito de falar, de dizer o que pensa e, ai, nós decide juntas (A3).

Na hora que é pra pegar no pé, pega mesmo. Na hora que é pra dizer isso tá errado, tá errado. E a gente ... eh... vamos aceitar. Você sabe que a verdade dói, mas você termina entendendo que ela tá certa. (A4).

Esse tipo de revelação reflete que o cotidiano do Grupo não é romântico, sem atritos ou conflitos. Ao contrário, como em qualquer outro tipo de organização, há conflitos, debates e divergências de opinião o que, claro, intervém no desempenho do grupo.

A construção da linha da vida do Grupo indicou que a evolução é notória nos campos social e político, com maior incidência, e econômico, com menos evidência. Mulheres, que antes não sabiam ler e nem escrever, hoje organizam balanços financeiros e treinamentos em cultivos e criação de animais. Mulheres, que antes não tinham recursos, sequer para comprar um creme de cabelo, hoje têm capacidades para discutir, propor e gerenciar assuntos políticos e sociais, além de domínio técnico em culturas agrícolas e criação de animais. Esse crescimento deve-se, em grande medida, ao modo como as associadas se relacionam, possivelmente alcançado a partir das várias formações que tiveram com Entidades de Apoio e Fomento (EAF) à Economia Solidaria.

O companheirismo e a sinceridade ajudam no fluxo das atividades por tornar as mulheres mais próximas e mutuamente confiantes. A Associada A3 deixa claro como essa relação ajuda no desempenho das atividades:

O coleguismo no trabalho ajuda! Não atrapalha, ajuda. Porque, eh.. é muito bom a gente tá trabalhando uma hora ai para; conversa um pedacinho e vai; depois continua tudo de novo. [ ...] Eu acho que ajuda, e muito, entendeu? Porque é muito bom a gente tá lá pra baixo e receber uma palavra amiga, é muito bom (A3).

Seja a partir das relações de trabalho, seja a partir dos relacionamentos interpessoais que estabelecem entre si, o Grupo estudado apresenta, com base na proposição teórica de Ramos (1989), traços de isonomia, com elevado grau de presença das cinco dimensões que o autor elenca para caracterizar tal enclave organizacional.

\section{Conclusões e Recomendações}

A partir da análise realizada, é possível chegar à conclusão de que no Grupo de Mulheres Decididas a Vencer encontram-se evidências do enclave isonomia na medida em que o cotidiano de trabalho e produção se aproxima do modelo heurístico proposto por Ramos (1989). Há mutualidade e satisfação nas relações interpessoais, chegando ao ponto de as associadas considerarem as atividades que realizam como terapia. O ambiente de trabalho permite flexibilidade no tratamento interpessoal e não há, a rigor, distância entre o universo do trabalho e a rotina diária da vida. Não há trâmites burocráticos no relacionamento entre elas, mesmo para aquelas que identificam uma associada como sendo a líder do Grupo. A relação é de descontração, cumplicidade, companheirismo e amizade, ainda que, por vezes, com presença de debates rígidos e decisões tomadas a partir de longas discussões, com dificuldades no alcance de consenso.

São relações primárias, com predominância da reciprocidade, sem imposições ou qualquer manifestação de autoridade superior ou de hierarquia. O Grupo Mulheres Decididas a Vencer, além de se enquadrar nos preceitos teóricos do que se concebe como Empreendimento Econômico Solidário, conforme entendem Singer (2002), Gaiger (2004), França Filho (2003, 2008), França Filho e Laville (2004) e Laville e Gaiger (2009), aproxima-se, também, dos traços do que Ramos (1989) configura como enclave isonomia.

Ao chegar a tal conclusão este estudo contribui para a superação do "impasse" de que os pressupostos guerreirianos não têm validade empírica, o que já foi anteriormente trabalhado por Serva (1997) e outros pesquisadores do universo das organizações. Aqui se demonstrou a existência de um sistema social que, apesar dos intercâmbios que estabelece com o enclave mercado, possui traços que o 
coloca no enclave isonomia. O entendimento de que possam existir sistemas sociais que convivem e ao mesmo tempo divergem em princípios basilares macros - como são os casos da economia e da isonomia conduz à aceitação do Paradigma Paraeconômico, conforme proposto por Ramos (1989), com categorias heurísticas que não se manifestam em estado puro e dialogam entre si.

A atribuição de significado ao trabalho na perspectiva de terapia, satisfação e autorealização supera a imputação convencionalmente encontrada, qual seja, aquela de trabalho como sinônimo de resultado econômico, sofrimento, remuneração e renda. Diferentemente da concepção convencional de trabalho com a finalidade de produção e geração de renda e ganhos econômicos - foi encontrada a ocupação, vinculada ao prazer de fazer aquilo que dá sentido à vida, pela via de relacionamentos primários (não hierarquizados), da amizade e da reciprocidade, dentre outros valores similares.

A possibilidade de sincronias entre Economia Solidária a isonomia mostrou-se factível. Todavia, o Grupo é pequeno (esta pesquisa envolveu seis mulheres na atividade de produção de hortaliças), tem história no ato associativo (está localizado em um assentamento rural da Reforma Agrária), produz e comercializa volumes reduzidos de mercadoria e, por esta razão, tem renda média com a atividade em torno de R\$120,00 ao mês, e é constituído exclusivamente por mulheres em situação similar de vida e trabalho. Resta um questionamento para futuras pesquisas sobre até que ponto a economia solidária pode colocar-se como um espaço próximo ao da isonomia. A viabilização de estudos que abranjam um número maior de empreendimentos ao mesmo tempo, no intuito de compará-los, ou mesmo de evidenciar os demais sistemas sociais a que se propõe o Paradigma Paraeconômico, poderia contribuir para responder tal questão.

\section{Notas}

1- Terreno ou território encravado em outro (Houaiss \& Villar, 2009) .).

2- O significado de autorrealização aqui envereda na concepção proposta por Maslow: “consecução do potencial, autodesenvolvimento, crescimento; dizem respeito ao desenvolvimento pessoal do indivíduo" (Park Bonis \& Abud, 1997, pp. 89-90).

3- Vocação no sentido de “[ ...] disposição natural e espontânea que orienta uma pessoa no sentido de uma atividade, uma função ou profissão; pendor, propensão, tendência" (Houaiss \& Villar, 2009) .).

4- Mutualidade no sentido de "[ ...] dar em recompensa ou em troca de algo similar; mutual, recíproco" (Houaiss \& Villar, 2009) .).

5- Fato Administrativo, na concepção de Ramos (1983, p. 7), é "um complexo de elementos e de suas relações entre si, resultante e condicionante da ação de diferentes pessoas, escalonadas em diferentes níveis de decisão, no desempenho de funções que limitam e orientam atividades humanas associadas, tendo em vista objetivos sistematicamente estabelecidos".

6- De acordo com Laville e Gaiger (2009) o primeiro a mencionar o termo empreendimento econômico solidário, introduzido pelas formulações acerca de economia popular, foi Luis Razeto, na década de 1980.

7- Para maiores informações sobre o cooperativismo operário de Robert Owen conferir Teixeira (2002). Utópicos, Heréticos e Malditos. São Paulo: Record.

8- Polanyi (2000) utilizou esses conceitos na sua literalidade: a reciprocidade é a o que se faz ou que se dá em recompensa ou em troca de algo similar, mútuo; redistribuição são as retenções operadas sobre as rendas (seja econômica ou não) de uns que são revertidas em benefício de outros (ou de si próprios); e domesticidade consiste na produção para o próprio uso. Para um melhor entendimento de como Polanyi (2000) contextualiza cada conceito conferir capítulo 4.

\section{Referências}

Bardin, L. (1977). Análise de conteúdo. Lisboa: Edições 70.

Costa, P. A. (2007). Inovação em economia solidária: um desafio no campo político. Tese de doutorado, Universidade Federal do Rio Grande do Sul, Porto Alegre, RS, Brasil.

França, G. \& Laville, J. L. (2004). Economia solidária: uma abordagem internacional. Porto Alegre: Editora da UFRGS.

França, G. (2002). Terceiro setor, economia social, economia solidária e economia popular: traçando fronteiras Conceituais. Revista Bahia Análise \& Dados, 12 (1), 9-20.

França, G. (2003). A temática da economia solidária e suas implicações originais para o campo dos estudos organizacionais. Revista de Administração Pública, 37 (1), 11-31. 
França, G. (2008). A via sustentável- solidária no desenvolvimento local. Revista Organização \& Sociedade, 15 (45), 219-232.

França, G. (2010). Decifrando a noção de paraeconomia em Guerreiro Ramos: a atualidade de sua proposição. Revista Organizações \& Sociedade, 17 (52), 175-197.

Flick, U. (2004). Uma introdução à pesquisa qualitativa (2. ed). Porto Alegre: Bookman.

Gaiger, L. I. (2004). A Economia solidária e o projeto de outra mundialização. Revista de Ciências Sociais, 47 (4), 799-834.

Gaiger, L. I. (2007). A Economia Solidária no Brasil: refletindo sobre os dados do primeiro Mapeamento Nacional. Anais do // Seminário Nacional do Núcleo de Pesquisa sobre Movimentos Sociais, Florianópolis, SC, Brasil.

Gaiger, L.I. (2003). A economia solidária diante do modo de produção capitalista. Caderno CRH,16 (39), 181-211.

Houaiss, A. \& Villar, M. (2009). Dicionário Houaiss da Língua Portuguesa. Rio de Janeiro: Objetiva.

Konder, L. (1998). Fourier, o socialismo do prazer. Rio de Janeiro: Civilização Brasileira.

Laville, J. L. \& Gaiger, L. I. (2009). Economia solidária. In: Cattani, A. D., Laville, J. L., Gaiger, L. I. \& Hespanha, P. Dicionário internacional da outra economia. São Paulo: Almedina.

Lechat, N. M. P. (2002). As raízes históricas da economia solidária e seu aparecimento no Brasil. // Seminário de Incubadoras Tecnológicas de Cooperativas Populares, Campinas, SP, Brasil.

Lisboa, A. M. (2005). Economia solidária e autogestão: imprecisões e limites. Revista de Administração de Empresas, 45 (3), 109-115.

Park, K. H., Bonis, D. F. de. \& Abud, M. R. (1997). Introdução ao Estudo da Administração. São Paulo: Pioneira.

Paula, A. P. P. de. (2007). Guerreiro Ramos: resgatando o pensamento de um sociólogo crítico das organizações. Revista Organização \& Sociedade, 40 (14), p. 169-188.

Polanyi, K. (1992). La gran transformación: los orígenes políticoss y econômicos de nuestro tiempo. México: Fondo de Cultura Económica.

Polanyi, K. (2000). A grande transformação: as origens da nossa época (2a ed.). Rio de Janeiro: Elsevier.

Ramos, A. G. (1983). Administração e contexto brasileiro - Esboço de uma teoria geral de administração. Rio de Janeiro: Editora da Fundação Getúlio Vargas.

Ramos, A. G. (1989). A nova ciência das organizações: uma reconceituacão da riqueza das nações (2a ed.). Rio de Janeiro: Editora da Fundação Getúlio Vargas.

Serva, M. (1997). A racionalidade substantiva demonstrada na prática administrativa. Revista de Administração de Empresas, 37 (2), 18-30.

SIES - Sistema Nacional de Economia Solidária. Atlas da economia solidária no Brasil. Brasília: SENAES/MTE, 2007.f

Singer, P. \& Souza, A. R. (2000). A economia solidária no Brasil: a autogestão como resposta ao desemprego ( 2 a ed.) São Paulo: Contexto.

Singer, P. (2002). Introdução à economia solidária. São Paulo: Editora Fundação Perseu Abramo.

Souza, W. J. \& Lins, N. B. (2007). Contormos da Isonomia: articulação entre elementos de racionalidade na gestão de uma ong. Revista Eletrônica de Ciências Administrativas, 6 (1), 1-14.

Teixeira, A. (2002). Utópicos, Heréticos e Malditos. São Paulo: Record.

Triviños, A. N. S. (2007). Introdução à pesquisa em ciências sociais: a pesquisa qualitativa em educação. São Paulo: Atlas.

Ventriss, C. \& Candler, G. G. (2005). Alberto Guerreiro Ramos, 20 years later: a new science still unrealized in an era of public cynicism and theoretical ambivalence. Public Administration Review, 65 (3), 347-359. 